\title{
Modeling of Sustainable Development of the Region on the Basis of Cognitive Analysis
}

\author{
Zakharova Elena Nikolaevna ${ }^{1} \&$ Prokhorova Victoria Vladimirovna ${ }^{2}$ \\ ${ }^{1}$ Head of Economy and Management Department, Adyghe State University, Maikop, Russian Federation \\ ${ }^{2}$ Kuban State Technological University, Russian Federation \\ Correspondence: Zakharova Elena Nikolaevna, Head of Economy and Management Department, Adyghe State \\ University, Maikop, Russian Federation. E-mail: zahar-e@yandex.ru
}

\author{
Received: September 19, 2014 Accepted: October 8, $2014 \quad$ Online Published: March 27, 2015 \\ doi:10.5539/ass.v1 $1 \mathrm{n} 7 \mathrm{p} 362$ \\ URL: http://dx.doi.org/10.5539/ass.v11n7p362
}

\begin{abstract}
The present study considers the possibility of applying the cognitive analysis to the modeling of sustainable development of the region. The study contains the definition and the classification of the main criteria for assessing the sustainability of the regional socio-economic system. The study offers the application of the cognitive approach as a powerful tool for the study of unstable environment and modeling of semi-structured systems. The author sets out the key provisions of the methodology and points out the stages of cognitive analysis of complex socio-economic systems. The present study illustrates the possibility of practical implementation of the methodology for the cognitive analysis and modeling of the regional socio-economic system on the example of the Chelyabinsk region. By constructing a matrix of the pair correlation the target and control factors have been selected, the analysis of the interaction of key indicators of social and economic stability of the region has been conducted. The validation of the developed model has proved the possibility of its use for predicting the target factors, modeling of possible situations and development of scenarios of strategies for sustainable development of the region.
\end{abstract}

Keywords: cognitive map, sustainable development, semi-structured system, socio-economic system, scenario modeling, regression model, correlation analysis

\section{Introduction}

One of the most discussed issues attracting the attention of scientists and practitioners at the state, regional and local levels of the management is the study of the management of sustainable development of the country as a whole and individual regions (Hollingsworth, 2005). Dynamism and diversity of the processes require an adequate choice of technique and instrumental apparatus that can facilitate the analysis of the problems and develop an optimal model for sustainable development of a particular area. The development of such a model shall be based on an array of qualitative and quantitative information sufficient for determination of the disparities and tendencies in the socio-economic development of the region and allowing to predict the dynamics of the processes (Bourgine, 2004).

Cognitive modeling is one of the effective tool allowing to obtain the required scope of the information and conduct the analysis of poorly formalized complex systems (Midlarsky, 1997).

\section{Methods}

In recent years, the basis for future developments in the study of the behavior of the problem-oriented complex systems has become a cognitive approach, which makes it relatively easy to represent the structure of the socio-economic system, identify the cause-effect relationships between the elements of the system, as well as to predict its further development.

The cognitive approach to the study of complex systems involves the solution of an interrelated set of problems of the system analysis, namely: identification of the object and the socio-economic environment in the form of the cognitive model; analysis of the cycles and directions of the cognitive model; conduct of the analysis on controllability, stability, sensitivity, adaptability; scenario analysis, etc. 
For solution of these problems there are many specific and general theoretical approaches and methods, which include the following methods: methods of expert, statistical, analytical identification, methods of graph theory, methods of control theory, methods of general systems theory, etc.

The development of contemporary management methods requires specifying the scenario conditions of socio-economic development of the region. The main methods of scenario analysis include scenario planning, situational analysis, surge modeling, etc.

\section{Results and Discussion}

The main indicator of the efficiency of functioning of the region representing a complex socio-economic system is the stability of its development.

In the course of ensuring the sustainable development there is a currently widespread concept of triple bottom line. In the framework of this concept economic results of an activity, as well as social and environmental impacts are taken into account (SGM, 2012).

The ability to maintain a stable economic situation and an increase in living standards of the population of the region is estimated using economic, social and environmental indicators. For each specific indicator set the thresholds, the violation of which leads to the formation of negative trends in socio-economic development of the region. Development of the region can be considered as stable if the actual level of indicators is within the permissible limits of the thresholds and the balance between the indicators characterizing the state of economic, social and environmental systems can be achieved (Grodach, 2011; Prokhorov, 2010).

The systems, characterized by the uncertainty and ambiguity of the assessments of the consequences of certain decisions, are called semi-structured systems. In order to describe the ongoing processes in such systems the qualitative information is primarily used, while the detailed quantitative description (as opposed to technical systems) is virtually absent (Kamaev, 2012).

The display of the qualitative transitions from one state to another is considerably difficult in constructing models of the semi-structured systems (White, 2009). When planning the measures to achieve sustainable (equilibrium) state of the object it is necessary to use the mathematical tools for the analysis of semi-structured problems of the complex systems, since the traditional mathematical approach to the analysis of the processes occurring in such systems is not possible. One of the most powerful tools used in the study of the unstable environment and modeling of the semi-structured systems is the cognitive (perceptive) analysis (Solis, 2014; Sadovnikova, 2012; Gorelova, 2005).

The cognitive analysis of such complex socio-economic system as a region shall allow to take the following measures:

- Conduct a comprehensive analysis of all the factors affecting the socio-economic development of the region;

- Take into account poorly formalized qualitative factors as well as quantitative factors;

- Conduct an analysis of the dynamics of indicators of sustainable development of the region;

- Generate and test hypotheses on the social and economic situation in the region;

- Carry out a scenario analysis of the development of the regional socio-economic system.

The key point of the cognitive analysis is the modeling, the essence of which is to reflect the complex problems and trends of the development in the form of a simplified model, as well as to study possible scenarios of manifestations of crisis situations and develop recommendations for dealing with their consequences.

The cognitive analysis is carried out in several stages (Sadovnikova, 2012; Gorelova, 2005):

1) The definition of the goals and objectives of the study;

2) The study of the situation. At this stage carried out the collection, compilation, systematization of the available information, both qualitative and quantitative, including the state of the environment in the region. Specified the requirements, conditions and limitations of the situation under the study;

3) Pointing out the problematic factors of sustainable development of the region;

4) Simplicial analysis (analysis of the system q-connectivity);

5) Verification of the cognitive model, i.e. testing of its validity;

6) Prediction of possible events, construction of various scenarios for the development of the system, the development and adoption of decisions on the management of the regional socio-economic system. 
The first two stages are preparatory, as a result of their realization formed the information base for further analysis. The choice of indicators is based on the principle of maximum relevance, i.e. selected only those indicators those are relevant to the characterization of sustainable development.

The set of basic factors of the sustainable development of the region can be grouped into three main units: economic, environmental and social units (Figure 1).

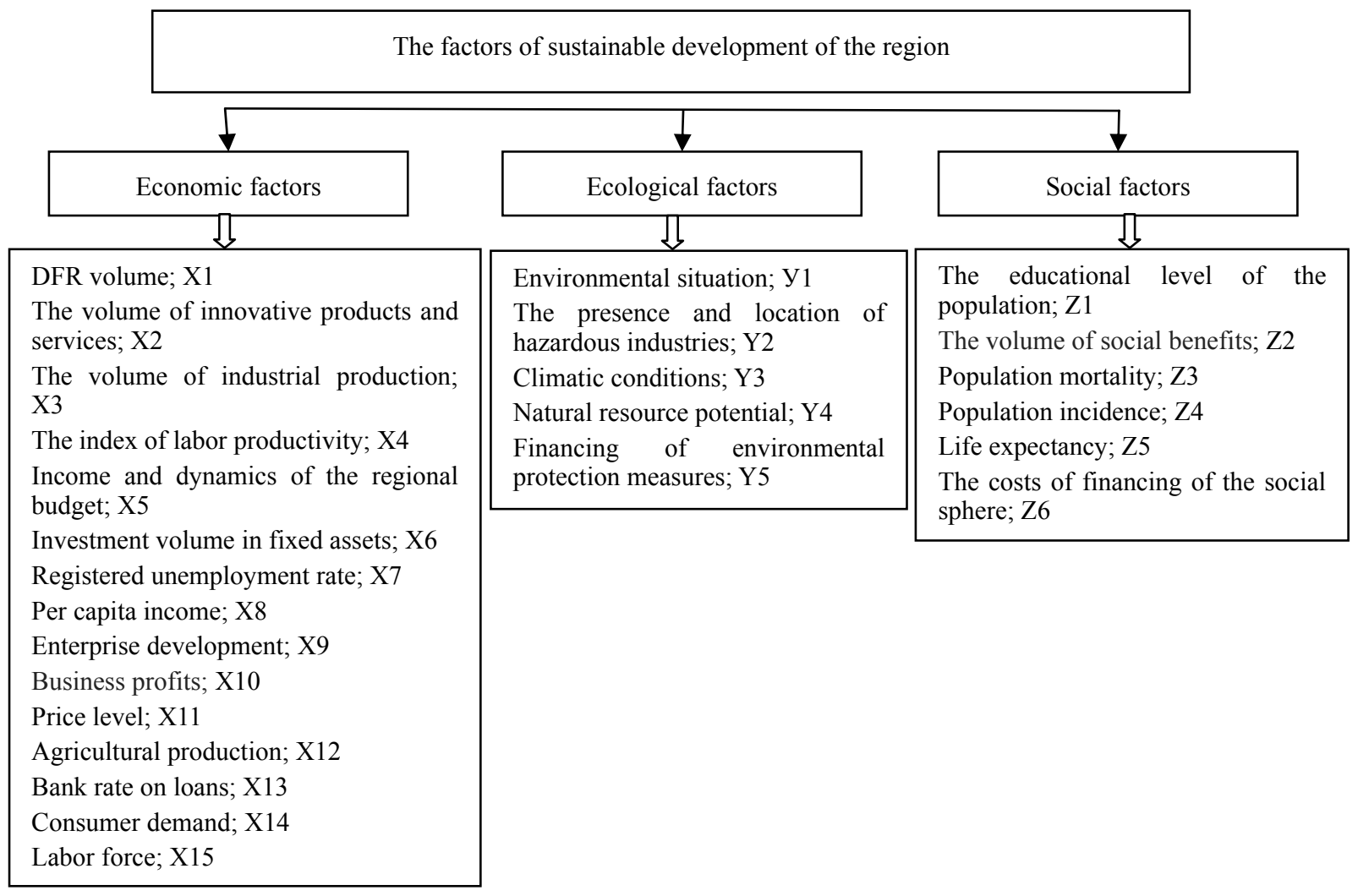

Figure 1. The factors of sustainable development of the region

The next stage is the separation of the factors on the target and control ones (Gorelova, 2005). Target factors are the factors which values are necessary to be changed in the framework of the given task, while control factors are the factors that can be used to influence the target factors. Along with control factors it is necessary to take into account uncontrollable factors directly or indirectly affecting the target factors as such factors can play a significant role in assessment of the attainability of goals (Pryor, 2005).

The stages 3 to 5 actually represent the cognitive modeling, resulting in a cognitive map and the weights of arcs of the functional graph.

The cognitive map is a directed weighted graph in which the vertices correspond to the factors of the system, while the arcs correspond to the interaction between them: $\mathrm{G}=\langle\mathrm{V}, \mathrm{E}\rangle$,

where $G$ is the weighted digraph; $V$ means a set of $v_{i}$ vertices being the factors of the system; $E$ means a set of $e_{i j}$ arcs reflecting the relationships between the vertices $i, j=1,2, \ldots \mathrm{k}$.

In practice, the determination of cause-effect relationships between the factors along with pointing out the signs of effects is based on expert knowledge of the problem situation. For modeling of problem situations 25 to 100 factors are normally used.

There are two types of cause-effect interaction between the factors: positive (direct) and negative (inverse) types. Solid lines and a symbol "+" means positive interaction between the vertices $\mathrm{Vi}$ and $\mathrm{Vj}$, i.e. an increasing (decreasing) influence of the factor $\mathrm{Vi}$ causes an increase (decrease) in the vertex $\mathrm{Vj}$, dot-dash lines and a symbol «-» means negative interaction between $\mathrm{Vi}$ and $\mathrm{Vj}$, i.e. an increasing (decreasing) influence of the factor Vi causes a decrease (increase) in the vertex V. 
However, the cognitive map captures only the fact of the interaction between the factors of the system without detailing the nature of these relationships and without regard to their dynamics (Gorelova, 2005; Zabolotsky, 2005). Specification of the parameters of the system, determination of the nature of relationships and the importance of the factors are carried out by constructing the cognitive model.

The cognitive model represents a functional graph of the studied system, in which the vertices correspond to the factors of the system, while the arcs reflect the functional interaction between them (Lavresh, 2011). Each case of interaction between the system factors can be expressed by both measurable (quantitative) and non-measurable (qualitative) variables.

Quantitative variables are expressed as numerical values. As an example, the main indicators of economic development of the Chelyabinsk region for the period of 2008-2012 have been considered (Table 1).

Table 1. Indicators of economic development of the Chelyabinsk region for the period of 2008-2012

\begin{tabular}{|c|c|c|c|c|c|c|}
\hline \multicolumn{2}{|c|}{ Factors } & \multirow{2}{*}{$\frac{2008}{664493}$} & \multirow{2}{*}{$\begin{array}{l}2009 \\
556985\end{array}$} & \multirow{2}{*}{$\begin{array}{l}2010 \\
652866\end{array}$} & \multirow{2}{*}{$\frac{2011}{775935}$} & \multirow{2}{*}{$\begin{array}{l}2012 \\
843339\end{array}$} \\
\hline $\mathrm{X} 1$ & Gross Regional Product, mln. RUB & & & & & \\
\hline $\mathrm{X} 2$ & The volume of innovative products and services, mln. RUB & 38300 & 14646.1 & 19351.6 & 29442.8 & 57635.7 \\
\hline $\mathrm{X} 3$ & Industrial output, mln. RUB & 720413 & 867013 & 604825 & 860046 & 1028924 \\
\hline $\mathrm{X} 4$ & Labor productivity index & 100.6 & 91.8 & 104.6 & 103.1 & 103.7 \\
\hline $\mathrm{X} 5$ & Regional budget income, mln. RUB & 105480 & 88252 & 109399 & 119399 & 130364 \\
\hline $\mathrm{X} 6$ & Investment volume in fixed assets, million RUB & 181006 & 145446 & 151122 & 176598 & 192816 \\
\hline X7 & Registered unemployment rate, $\%$ & 1.8 & 3.6 & 2.3 & 1.7 & 1.5 \\
\hline $\mathrm{X} 8$ & Per capita population income, RUB per month & 14120 & 15215.1 & 16821.1 & 18459.9 & 19366.2 \\
\hline X9 & Turnover of small businesses, bln. RUB & 341.9 & 321.1 & 462.1 & 487.5 & 479.6 \\
\hline $\mathrm{X} 10$ & Profit of the enterprises, mln. RUB & 68667 & 66351 & 76816 & 48312 & 70597 \\
\hline $\mathrm{X} 11$ & Price level & 112.8 & 108.6 & 109.6 & 108.3 & 106.3 \\
\hline $\mathrm{X} 12$ & Agricultural production, mln. RUB & 62672.7 & 62174.2 & 60195.3 & 84384.6 & 69605.7 \\
\hline $\mathrm{X} 13$ & Average annual bank rate, $\%$ & 12.3 & 15.2 & 10.8 & 8.5 & 9.9 \\
\hline $\mathrm{X} 14$ & Household expenses on final consumption per capita, RUB & 147098 & 149833 & 161329 & 186813.6 & 203915.4 \\
\hline $\mathrm{X} 15$ & Labor force, thousand people & 1851 & 1854 & 1871 & 1882 & 1879 \\
\hline
\end{tabular}

In order to obtain the final assessment of interaction of the factors of economic development prepared the matrix of pairwise correlation (Noskov, 2013). A sample of this matrix is shown in Table 2.

Table 2. Matrix of pairwise correlation of the factors of economic development of the Chelyabinsk region

\begin{tabular}{|c|c|c|c|c|c|c|c|c|c|c|c|c|c|c|c|}
\hline & $X 1$ & $X 2$ & $X 3$ & $X 4$ & $X 5$ & $X 6$ & $X 7$ & $X 8$ & $X 9$ & $X 10$ & $X 11$ & $X 12$ & $X 13$ & $X 14$ & $X 15$ \\
\hline $\mathrm{X} 1$ & & & & & & 0.86 & -0.87 & 0.83 & 0.79 & -0.28 & -0.51 & 0.64 & -0.86 & 0.93 & 0.80 \\
\hline $\mathrm{X} 2$ & 083 & 1.00 & 0.59 & 0.49 & 0.79 & 0.94 & -0.77 & 0.48 & 0.37 & 0.05 & -0.27 & 0.24 & -0.48 & 0.68 & 0.35 \\
\hline X3 & 0.55 & 0.59 & 1.00 & -0.16 & 0.41 & 0.52 & -0.15 & 0.56 & 0.18 & -0.34 & -0.73 & 0.46 & -0.13 & 0.69 & 0.35 \\
\hline X4 & 0.73 & 0.49 & -0.16 & 1.00 & 0.83 & 0.54 & -0.87 & 0.57 & 0.83 & 0.05 & -0.09 & 0.32 & -0.89 & 0.56 & 0.69 \\
\hline X5 & 0.98 & 0.79 & 0.41 & 0.83 & 1.00 & 0.80 & -0.89 & 0.83 & 0.86 & -0.15 & -0.47 & 0.55 & -0.89 & 0.90 & 0.82 \\
\hline X6 & 0.86 & 0.94 & 0.52 & 0.54 & 0.80 & 1.00 & -0.87 & 0.44 & 0.40 & -0.22 & -0.13 & 0.47 & -0.60 & 0.64 & 0.38 \\
\hline X7 & -0.87 & -0.77 & -0.15 & -0.87 & -0.89 & -0.87 & 1.00 & -0.51 & -0.66 & 0.17 & 0.03 & -0.48 & 0.85 & -0.62 & -0.57 \\
\hline X8 & 0.83 & 0.48 & 0.56 & 0.57 & 0.83 & 0.44 & -0.51 & 1.00 & 0.90 & -0.27 & -0.85 & 0.63 & -0.77 & 0.97 & 0.96 \\
\hline X9 & 0.79 & 0.37 & 0.18 & 0.83 & 0.86 & 0.40 & -0.66 & 0.90 & 1.00 & -0.21 & -0.57 & 0.59 & -0.92 & 0.83 & 0.97 \\
\hline X10 & -0.28 & 0.05 & -0.34 & 0.05 & -0.15 & -0.22 & 0.17 & -0.27 & -0.21 & 1.00 & 0.16 & -0.90 & 0.38 & -0.29 & -0.35 \\
\hline X11 & -0.51 & -0.27 & -0.73 & -0.09 & -0.47 & -0.13 & 0.03 & -0.85 & -0.57 & 0.16 & 1.00 & -0.41 & 0.31 & -0.80 & -0.71 \\
\hline X12 & 0.64 & 0.24 & 0.46 & 0.32 & 0.55 & 0.47 & -0.48 & 0.63 & 0.59 & -0.90 & -0.41 & 1.00 & -0.71 & 0.65 & 0.70 \\
\hline X13 & -0.86 & -0.48 & -0.13 & -0.89 & -0.89 & -0.60 & 0.85 & -0.77 & -0.92 & 0.38 & 0.31 & -0.71 & 1.00 & -0.76 & -0.88 \\
\hline X14 & 0.93 & 0.68 & 0.69 & 0.56 & 0.90 & 0.64 & -0.62 & 0.97 & 0.83 & -0.29 & -0.80 & 0.65 & -0.76 & 1.00 & 0.89 \\
\hline X15 & 0.80 & 0.35 & 0.35 & 0.69 & 0.82 & 0.38 & -0.57 & 0.96 & 0.97 & -0.35 & -0.71 & 0.70 & -0.88 & 0.89 & 1.00 \\
\hline
\end{tabular}


The qualitative parameters of the system are described by linguistic variables, the numerical value of each of which are defined on the scale [-1, 1]: "extremely strong"; "strong"; "significant"; "moderate"; "extremely weak" (Baranyuk, 2014).

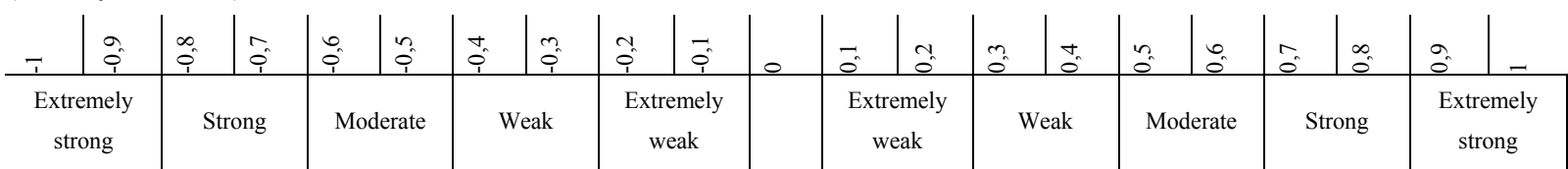

After determining the level of interaction of the factors each arc of the cognitive map represents the functional interaction, i.e. the cognitive model can be represented as a functional graph. Collectively the cognitive model of sustainable development of the Chelyabinsk region, reflecting the interaction of the factors of economic, ecological and social subsystems, is exposed in Figure 2.

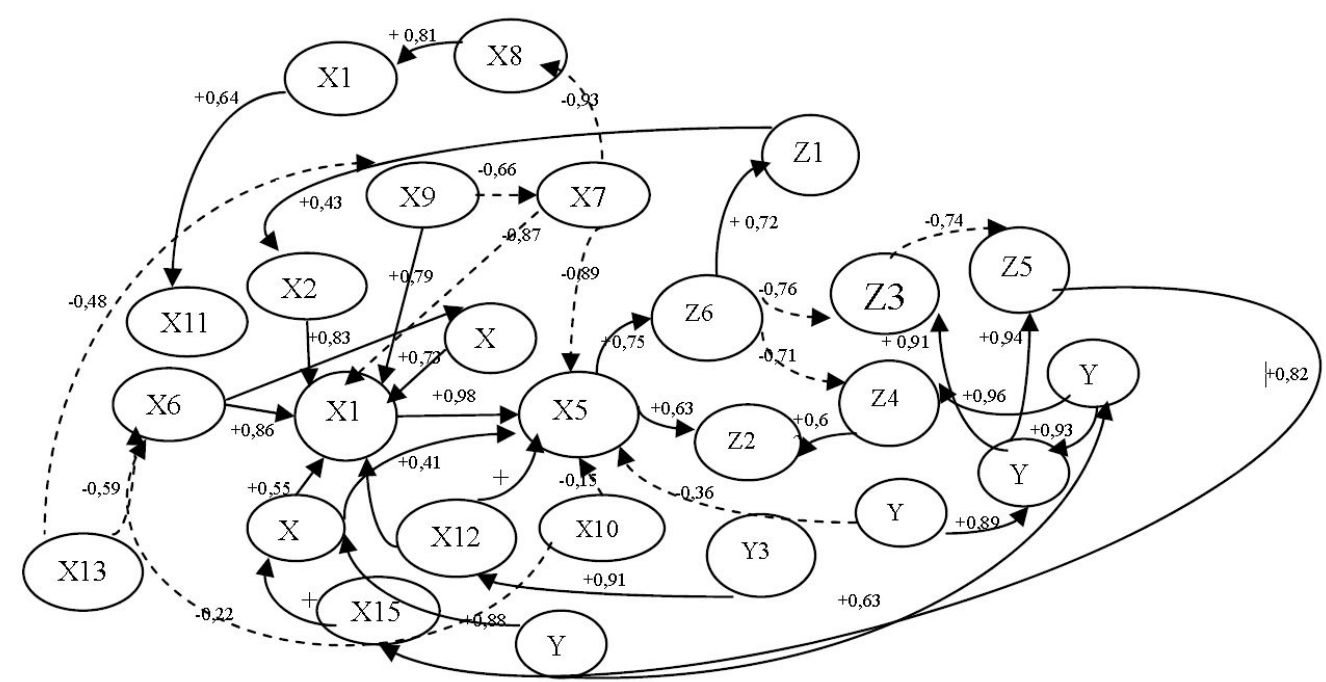

Figure 2. Fragment of the cognitive model of sustainable development of the Chelyabinsk region

According to the results of the conducted analysis on interaction of the factors of sustainable development of the Chelyabinsk region, it can be concluded that there is an extremely strong interaction between GRP volume (X1) and fiscal revenues (X5); between the volume of investment (X6) and the production of innovative goods and services (X2); ecological situation in the region (Y1) with the placement of unhealthy trade (Y2), mortality (Z4) and morbidity of the population (Z5).

In consideration of expansion of the disturbance process in the cognitive model, it was determined that the most affected ones occurred the indicators X1, X5 (gross regional product and regional budget income). These factors can be identified as target indicators of sustainable development of the region.

The target factor X1 is influenced by the following factors: X2 - the volume of innovative products, X9 - the turnover of small enterprises, X12 - the production of agricultural products. They can be called control factors.

In order to analyze the dynamics of the factors, as well as to change and determine the degree of their impact on the indicator X1, constructed the regression model (Basilevsky, 2010). As a result of processing the initial data received the following regression equation:

$$
36952+0.00338 \mathrm{X}_{3}+2.8 \mathrm{X}_{12}+3.99 \mathrm{X}_{2}+592.07 \mathrm{X}_{9}
$$

As it can be seen by equation (1) a differential of Factor 3 has a value of less than 0.05 , thus this indicator is excluded from the assessment as insignificant and having the inconclusive statistical reliability.

The final model consists of factors such as $\mathrm{X} 12$; $\mathrm{X} 2$; $\mathrm{X} 9$, whose differentials are rather significant.

The management of the regression takes the following form:

$$
134727.8+2.8 \mathrm{X}_{12}+4 \mathrm{X}_{2}+589.71 \mathrm{X}_{9}
$$

The target factor $\mathrm{X}_{5}$ is influenced by the following factors: $\mathrm{X} 1$ - GRP volume, $\mathrm{X}_{10}$ - profits of the enterprises, $\mathrm{X}_{6}$ - the investment volume in fixed assets. 
The management of the regression for the target factor "regional budget income" takes the following form:

$$
3988.5+0.16 \mathrm{X}_{1}+0.21 \mathrm{X}_{10}-0.12 \mathrm{X}_{6}
$$

In order to assess the significance of the obtained values of sustainability criteria the Student $\mathrm{t}$-test has been used. Its measured values for obtained models are indicated in Table 3.

Table 3. The value of the Student's t-test

\begin{tabular}{ccccccc}
\hline & \multicolumn{3}{c}{ Model 1 } & \multicolumn{3}{c}{ Model 2 } \\
\cline { 2 - 6 } & $\mathrm{X} 12$ & $\mathrm{X} 2$ & $\mathrm{X} 9$ & $\mathrm{X} 1$ & $\mathrm{X} 10$ & $\mathrm{X} 6$ \\
\hline Values of the Student t-test & 60.26 & 169.8 & 98.3 & 4.91 & 1.12 & -0.66 \\
\hline
\end{tabular}

If the value of t-test exceeds 1 , then its value is deemed satisfactory. The data of Table 3 show that the most significant and dominating factor for increasing GRP is the volume of innovative products. Control factors of the target indicator "regional budget income" (except for the factor X6) are also rather significant.

The next step is to review the validity of the obtained regression models, according to the criteria presented in Table 4.

Table 4. Validity criteria of the regression models of the GRP dynamics and regional budget income of the Chelyabinsk region

\begin{tabular}{ccc}
\hline Indicators & Model 1 & Model 2 \\
\hline $\mathrm{R}-$ multiple determination coefficient & 0.999994 & 0.992848 \\
$\mathrm{R}^{2}$ - determination coefficient & 0.999989 & 0.985748 \\
$\mathrm{~F}-$ Fisher`s ratio & 30062.59 & 23.06 \\
\hline
\end{tabular}

The determination criterion both in the first and the second model is close to 1 that indicates high "functionality" of the equations obtained. Multiple correlation coefficient representing the square root of the determination coefficient, shows close interaction between the dependent variables with three factors included in the model. High information content of the presented mathematical models is also confirmed by the value of F-test, i.e. the presented regression equations shall be considered as significant and they can be used for further analysis and prediction of the target factors of sustainable development of the region.

The attained results allow to give the following interpretation of the integrated cognitive model of sustainable development of the Chelyabinsk region:

- An increase in volumes of agricultural production per 1 million rubles shall allow to increase the volume of GRP by 2.8 million rubles at the constant turnover of small businesses and at the existing volume of production of innovative products and services;

- An increase in production of innovative goods and services per 1 million rubles for the same volume of A.I.C. production and at the same time the turnover of small enterprises in the region shall lead to an increase in DFR by 4 million rubles;

- The growth of the turnover of small enterprises per 1 million rubles at the constant volume of agricultural industry and production of innovative goods and services shall increase GDP by 589.71 million rubles.

It can be concluded that an increase of the indicators positively depending on the selected target indicators, have a positive effect on the general level of sustainable development of the Chelyabinsk region.

Similarly, the model of sustainable development is constructed, taking into account the qualitative indicators, which include, for instance, the educational level of the population, environmental situation, climatic conditions, natural resources potential and others. In most cases the qualitative indicators are evaluated by expert scoring method.

In order to evaluate the educational level of the population, environmental situation, natural resources potential of the region, can be used the integral indexes, which present a combination of individual partial criteria with a specific weighting factor. In calculating each of the partial criteria applied the fixed standards of minimum and maximum values for all regions of the Russian Federation which can be compared with the actual indicators of a particular region by the following formula: 


$$
J_{x i}=\frac{x_{a c t}-x_{\min }}{x_{\text {max }}-x_{\text {min }}} \cdot N
$$

where $\mathrm{x}_{\mathrm{act}}$ - means the actual value of the indicator for the particular region;

$\mathrm{X}_{\min }$ - means the minimum value of the indicator among the regions of the Russian Federation;

$\mathrm{X}_{\max }$ - means the maximum value of the indicator among the regions of the Russian Federation;

$\mathrm{N}$ - means the weighing factor.

The indexes of the reverse indicators are calculated by the following formula:

$$
J_{x i}=\frac{x_{\max }-x_{a c t}}{x_{i \max }-x_{i \min }} \cdot N
$$

For instance, the assessment of the environmental situation in the region can be made using the following criteria: the amount of emissions of air pollutants, the volume of recycled hazardous substances, water withdrawal from natural water sources, wastewater discharge into surface water bodies.

The information base for such an assessment shall be the data of the Federal State Statistics Service of the Russian Federation and its territorial bodies "Basic indicators of the environment".

An example of the assessment of the environmental situation in the Chelyabinsk region is presented in Table 5.

\begin{tabular}{|c|c|c|c|c|c|}
\hline Indicators & $\begin{array}{l}\text { Actual } \\
\text { value } \\
\left(\mathrm{X}_{\mathrm{act}}\right)\end{array}$ & $\begin{array}{c}\text { Minimum } \\
\text { value }\left(\mathrm{X}_{\min }\right)\end{array}$ & $\begin{array}{c}\text { Maximum } \\
\text { value }\left(\mathrm{X}_{\max }\right)\end{array}$ & $\begin{array}{l}\text { Weighing } \\
\text { factor }(\mathrm{N})\end{array}$ & $\begin{array}{l}\text { Integral } \\
\text { indicator } \\
\text { (I) }\end{array}$ \\
\hline $\begin{array}{l}\text { Emission of pollutants into the } \\
\text { atmosphere - in total, thousand tons }\end{array}$ & 678.0 & 0.2 & $3,520.0$ & 0.4 & 0.32 \\
\hline $\begin{array}{l}\text { The amount of harmful substances } \\
\text { used (recycled), thousand tons }\end{array}$ & $1,351.1$ & 0.0 & $5,807.7$ & 0.3 & 0.07 \\
\hline $\begin{array}{l}\text { Water withdrawal from natural water } \\
\text { sources for use, mln. cu.m. }\end{array}$ & 759 & 23.0 & 5,579 & 0.1 & 0.09 \\
\hline $\begin{array}{l}\text { Wastewater discharge into surface } \\
\text { water bodies }\end{array}$ & 842 & 4.2 & 5,292 & 0.2 & 0.17 \\
\hline Total amount & - & - & - & 1.0 & 0.65 \\
\hline
\end{tabular}

Table 5. An example of the assessment of the environmental situation in the Chelyabinsk region

Further constructed a regression model, which allows to determine the dynamics, as well as the degree of the influence of the factors on the level of environmental situation.

The initial data for this model are presented in Table 6.

Table 6. The initial data for construction of the model used for determination of the influence of the factors on the level of environmental situation in the Chelyabinsk region

\begin{tabular}{ccc}
\hline $\begin{array}{c}\text { The index of ecological } \\
\text { situation (Y) }\end{array}$ & $\begin{array}{c}\text { Number of enterprises with stationary sources of air } \\
\text { pollution, thousand units (Y2) }\end{array}$ & $\begin{array}{c}\text { Environmental cost, } \\
\text { mln. rub (Y5) }\end{array}$ \\
\hline 0.53 & 0.895 & $5,922.2$ \\
0.6 & 0.727 & 6,032 \\
0.62 & 0.721 & 6,270 \\
0.63 & 0.713 & $8,833.4$ \\
0.65 & 0.638 & 9,168 \\
\hline
\end{tabular}


The regression control for the target factor Y1 - "index of ecological situation of the region" has the following form:

$$
0.93-0.45 \mathrm{Y}_{2}+0.001876 \mathrm{Y}_{5}
$$

The value of t-criterion $(-5.04)$ shows that the most important factor to improve the overall environmental situation in the region is the number of enterprises with hazardous industries.

Thus, the obtained data allow to predict the development of the ecological situation in the region, based on the following assumptions:

- Reducing the number of enterprises with stationary sources of air pollution shall allow to improve the ecological situation in the region by 0.45 percentage points;

- An increase in the environmental financing by 1 (one) million rubles without reducing the amount of hazardous industries in the region shall allow to improve the integral indicator of the environmental situation by 0.002 percentage points only.

When constructing the general forecast model of sustainable socio-economic development of the region the analysis of the influence of qualitative indicators shall be carried out in a similar manner.

Specific software systems of cognitive modeling, for instance, "Situation", "Kanva", the integrated system "Course" and others, shall allow to reduce the number of errors made in the construction of the general forecast model of the sustainable development in the region, taking into account the quantitative and qualitative factors.

The further strategy of sustainable development of the region shall provide a system solution to the problems of development of the territory, providing for the possibility of financial and resource support of the implementation of measures and the assessment of their effectiveness.

\section{Conclusion}

Thus the formation of the regional strategy for sustainable development can be carried out using the method of cognitive modeling, which allows to develop different scenarios of the development of such a complex system as a socio-economic regional system. Cognitive modeling allows to develop a number of scenarios of the development that provides better adaptability of the final strategy due to the possible multiple solution of the problems of sustainable development of the region.

\section{References}

Baranyuk, V., \& Smirnov, O. (2014, June 16-19). Extending the scope of obtaining the information in order to solve the problems of the analysis in situation centers. Materials of XII All-Russian Conference on Control Problems VSPU-2014, Moscow.

Bazilevsky, M., \& Noskov, S. (2010). The algorithm for the formation of the set of regression models using the transformation of the dependent variable. International Journal of applied and fundamental research, 3, 159-160.

Bourgine, P., \& Nadal, J. (2004). Cognitive Economics: An Interdisciplinary Approach. New York, NY: Springer Science \& Business Media. http://dx.doi.org/10.1007/978-3-540-24708-1

Gorelova, G., Zakharova, E., \& Ginis, L. (2005). The cognitive analysis and modeling of sustainable development of socio-economic systems. Rostov-on-Don: RSU Publishers.

Gorelova, G., Zakharova, E., \& Radchenko, S. (2006). The study of semistructured problems of socio-economic systems: the cognitive approach. Rostov-on-Don: RSU Publishers.

Grodach, K. (2011, August). Obstacles to sustainable economic development: Dallas-Fort Worth experience. Cities, 4(28), 300-309.

Hollingsworth, J., Müller, K., \& Hollingsworth, E. (2005). Advancing Socio-Economics: An Institutionalist Perspective. Lanham, MD: Rowman \& Littlefield.

Kamaev, V. (2012). Cognitive modeling of socio-economic systems. Volgograd: IUNL VolgGTU.

Lavresh, I., Mironov, V., \& Smirnov, A. (2011). Cognitive modeling of socio-economic ratings of the regions. Bulletin of ITARK, 1, 24-32.

Midlarsky, M. (1997). Inequality, democracy, and economic development. Cambridge, UK: Cambridge University Press.

Noskov, S., \& Kirillova, T. (2013). Mathematical model of interference of factors of economic development of 
the territory. Fundamental research, 6(4), 892-894.

Prokhorova, V. (2010). Subregional resources and tools of intensive development of territorial economic systems of modern Russia. Moscow: Moscow University Press.

Pryor, F. (2005). Economic systems of foraging, agricultural, and industrial societies. Cambridge: Cambridge University Press. http://dx.doi.org/10.1017/CBO9780511754302

Rating of sustainable development of cities of the Russian Federation for 2012. (2012). Rating Agency SGM. Retrieved September 9, 2014, from http://agencysgm.com/upload/iblock/66b/reyting_2012.pdf

Sadovnikova, N., \& Zhidkova, N. (2012). The choice of spatial development strategies based on the cognitive analysis and scenario modeling. Internet Bulletin of VolgGASU, Construction Informatics Series, 7(21). Retrieved September 9, 2014, from http://www.vestnik.vgasu.ru

Solis, F., \& O'Brien, W. (2014, April). The critical assessment of the cognitive methods of analysis in construction management. Automatisierung im Bauwesen, 15(40), 21-32.

White, C. (2009). Understanding economic development: The global transition from poverty to prosperity? Cheltenham, UK: Edward Elgar.

Zabolotsky, M., Polyakova, I., \& Tikhonin, A. (2005). Cognitive modeling as a unique tool for analyzing and managing complex systems (region, industry, large enterprise). Successes of contemporary natural science, 2,28 .

\section{Copyrights}

Copyright for this article is retained by the author(s), with first publication rights granted to the journal.

This is an open-access article distributed under the terms and conditions of the Creative Commons Attribution license (http://creativecommons.org/licenses/by/3.0/). 